\title{
2p21 microdeletion syndrome
}

INSERM

\section{Source}

INSERM. (1999). Orphanet: an online rare disease and orphan drug data base. 2 p21

microdeletion syndrome. ORPHA:163693

The 2p21 microdeletion syndrome consists of cystinuria, neonatal seizures, hypotonia, severe growthand developmental delay, facial dysmorphism, and lactic acidemia. 